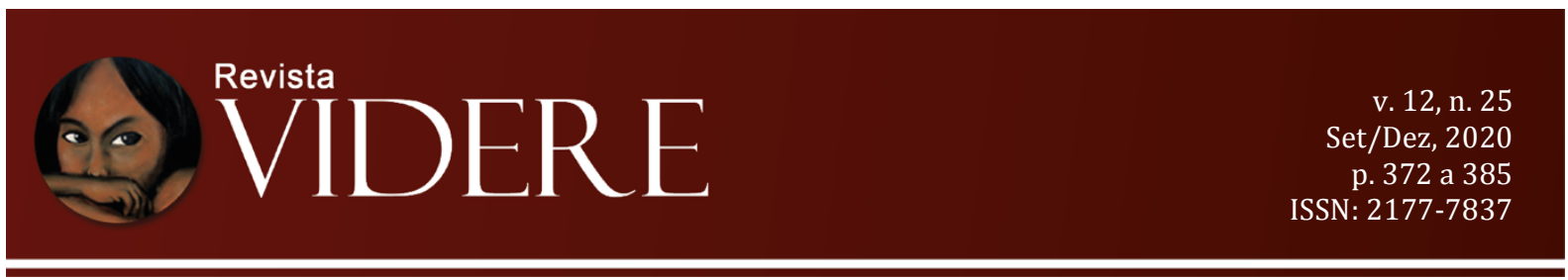

\title{
A GLOBALIZAÇÃO E A PROTEÇÃO DOS DIREITOS HUMANOS NO MUNDO DIGITAL
}

\author{
GLOBALIZATION AND THE PROTECTION OF HUMAN RIGHTS IN THE DIGITAL \\ WORLD
}
GLOBALIZACIÓN Y PROTECCIÓN DE LOS DERECHOS HUMANOS EN EL MUNDO DIGITAL

Luc Marie Quoniam
Doutor em Ciências da Informação e da Comunicação na Université Aix Marseille III
Professor da Université du Sud-Toulon Var. Toulon, France. Professor visitante da
Universidade Federal Mato Grosso do Sul, Brasil.
mail@guoniam.info
Orcid: https://orcid.org/0000-0002-6333-6594

Antonio Hilario Aguilera Urquiza

Doutorado em Antropologia (Salamanca/Espanha)

Professor da UFMS (Brasil)

hilarioaguilera@gmail.com

OrcID: http://orcid.org/0000-0002-3375-8630

Nilza Emy Yamasaki

Mestranda em Direito na UFMS (Brasil)

Diretora da AGINOVA - UFMS (Brasil)

nilza.yamasaki@,ufms.br

OrcID: https://orcid.org/0000-0001-9964-3185

\begin{abstract}
RESUMO: O presente artigo examina o processo de globalização e o surgimento da sociedade da informação, analisando os impactos decorrentes sobre os direitos humanos. Trata ainda de como a tecnologia tem contribuído para acelerar assimetrias no mundo contemporâneo, ao tempo em que permite ondas de resistência, geradas de forma rápida e dinâmica a partir da massa de conhecimento disponível, possibilitando articulação entre grupos de indivíduos em torno de variadas pautas de natureza social e ambiental. Lidar com esse desafio leva à necessidade de construir as bases, inclusive com a proteção de direitos, para cooperação tecnológica, política, econômica e cultural que permita aproveitar o mundo digital e seu potencial de conexões e mobilidade para propor soluções efetivas e equânimes para os problemas do mundo.
\end{abstract}

Palavras-chave: Globalização. sociedade da informação. direitos humanos. privacidade. 


\begin{abstract}
This article examines the globalization process and the emergence of the information society, analyzing the resulting impacts on human rights. It also deals with how technology has contributed to accelerate asymmetries in the contemporary world, while allowing waves of resistance, generated quickly and dynamically from the mass of available knowledge, allowing articulation between groups of individuals around varied social and environmental agendas. Dealing with this challenge leads to the need to build the foundations, including the protection of rights, for technological, political, economic and cultural cooperation that allows taking advantage of the digital world and its potential for connections and mobility to propose effective and equitable solutions to problems of the world.
\end{abstract}

Keywords: Globalization. information society. human rights. privacy.

RESUMEN: EL presente artículo examina el proceso de globalización y el surgimiento de la sociedad de la información, analizando los impactos resultantes acerca de los derechos humanos. También trata de como la tecnología ha contribuido para acelerar las asimetrías en el mundo contemporáneo, al tiempo en que permite olas de resistencia, generadas de forma rápida y dinámica a partir de la masa de conocimiento disponible, posibilitando la articulación entre grupos de individuos en torno a variadas pautas de naturaleza social y ambiental. Tratar con ese desafío lleva a la necesidad de construir las bases, incluso con la protección de derechos, para una cooperación tecnológica, política, económica y cultural que permita aprovechar el mundo digital y su potencial de conexiones y movilidad para proponer soluciones efectivas y ecuánimes a los problemas del mundo.

Palabras-clave: Globalización. sociedad de la información. derechos humanos. privacidad.

\title{
1 Introdução
}

A globalização é um fenômeno inequívoco que tem testado e acelerado a dinâmica social, produzindo reatividades e a busca por legitimar novas formas de organização social, em contraponto a uma visão de mundo homogeneizada e com base nos pressupostos da visão ideal de mundo impregnada por valores ocidentais. Nasceu com o viés econômico, mas foi se ampliando em tamanha monta que as culturas, as identidades, as fronteiras, a política, entre outros aspectos da vida em sociedade, foram se impregnando e se interlaçando nesta rede de conexões.

Tal estágio foi possível por crédito e culpa do forte e contínuo desenvolvimento tecnológico, a partir do advento do computador, e da disponibilidade de meios em especial a internet. Com esses avanços, as distâncias foram se encurtando e o pensamento e a ação dos homens foi sendo dirigido do individual e local para o global.

Criaram-se novas necessidades, seguindo inicialmente uma lógica capitalista de mercado, que buscava democratizar acessos a serviços e se reverter em movimentação de mais bens e mais produção. Nesse contexto, a informação passou de mero resultado para uma 
posição estratégica: tornou-se valor econômico e político, e pré-condição de poder se movimentar nessa aldeia de globalidades.

A tecnologia para tratar informações, que iniciou com simplificações e execução de cálculos matemáticos, hoje praticamente comanda a comunicação e a interação no planeta, com suas mensagerias instantâneas, mídias sociais, plataformas digitais. Fundou-se uma nova ordem social, a sociedade da informação, e criou um vínculo de dependência do elemento humano do mundo digital, ainda que alguns não usufruam diretamente dele.

Com a democratização da internet e das plataformas móveis, relativizou-se o distante, o tempo e o conhecimento. Pessoas se aproximaram; ideias ganharam agilidade na propagação; e um mundo de novos saberes e identidades pôde ser visto da palma da mão de cada indivíduo, por meio de seus aparelhos de telefonia móvel.

De outro lado, havia espaço desregulado para disseminar e apresentar padrões de comportamento individuais, coletivos, de natureza econômica, social e cultural, como compromissos e metas desejáveis para a toda a humanidade. Esse esforço buscava estabelecer um design global da própria existência humana e encaixá-la num modelo ideal de convivência, de condução, de pensar e agir, e até estético.

Preservar direitos dentro de uma sociedade globalizada tem gerado bons desafios aos pensadores do presente, refletindo sobre o passado e de olho em apontar caminhos para uma dimensão mais equânime e sustentável de futuro. É que a globalização, diferente de outros momentos históricos em que se opunham forças antagônicas (praticamente duais), promove uma multiplicidade de interesses e conflitos, ao tempo em que se percebe que esse fenômeno deslocou o homem do seu próprio lugar, deixando-se flanando nesse espaço virtual e de perceber seu papel crítico nesse palco de manobras.

Para preservar os direitos é preciso que o titular deles, o usuário de tecnologia, esteja atento às consequências que a inconsciência no uso das redes e das informações digitais podem lhe trazer. Viver informado na sociedade digital não pode ser sinônimo de estar vigiado e instado a todo momento a adotar ações sugestionadas pela máquina, cada vez mais conhecedora do indivíduo em seus gostos, interesses e predileções.

Essa onisciência, manifesta diariamente a cada acesso à internet, ocorre não por ação de forças sobrenaturais ou de exercícios de adivinhação. Os dados e traços que o usuário de tecnologia deposita livre e inocentemente na rede, ao saciar e tomar suas doses de 
informação, vêm sendo capturados, tratados e convertidos em verdadeiros instrumentos de poder direcionados a objetivos de consumo, ideológicos e políticos.

O domínio das tecnologias de big data (tratamento de grandes quantidades de dados) parece desequilibrar ainda mais o jogo de forças e acentua as assimetrias na sociedade. Acende-se o alerta para que esse processo não comprometa gravemente a igualdade, a liberdade e a capacidade do homem poder se desenvolver em sociedade. Se nada for feito, esse sujeito de direitos poderá acabar como mero joguete de uma sociedade digital, incapacitado de um pensar, de uma produção de saber e de tomar decisões autônomas para fins de sua preservação histórica e evolução.

Identificar os direitos humanos mais afetados nesse processo de globalização, no que toca o mundo digital, permitirá compreender de que forma eles podem ser melhor protegidos e realizados com efetividade. Tomando a globalização como um processo irreversível, estruturar a proteção desses os direitos, customizando-a e habilitando-a para funcionar nesse universo de dinâmica, dissenso e instantaneidade, possibilitará garantir as conquistas históricas e possibilitará um futuro de preservação da dignidade humana.

\section{A globalização e a sociedade da informação}

A humanidade tem naturalmente uma ânsia por conexão. Viajar, olhar o mundo e se fixar em alguma geografia mais favorável estava presente desde os primórdios dos ancestrais do homem. Esse movimento se intensificou com os meios de transportes, que permitiram expedições exploratórias e a expansão colonial, com um viés econômico e de dominação.

Em decorrência dessas viagens foram introduzidas novidades e promovidas modificações culturais que demonstram a influência o quanto existe de interconexão entre as sociedades. A massa e o sorvete chineses são um elemento da cultura italiana; o fumo dos indígenas avançou pelo globo e é uma grande indústria e um grave problema de saúde; a comunicação escrita substituiu a transmissão oral de conhecimentos.

O conceito de globalização é assim sintetizado pelo professor Jesus Lima Torrado:

(...) proceso amplio, contradictorio, complejo, heterogéneo y profundo de cambio en las relaciones entre sociedades, naciones y culturas que ha generado una dinámica de interdependencia en las esferas económica, política y cultural en las que se desenvuelve el actual proceso de mundialización y que hace posible que acontecimientos, decisiones y actividades ocurridas en un determinado lugar del 
planeta repercutan de forma muy significativa en otros lugares, en otras sociedades y en otras personas (TORRADO, 2000, p.47).

Entrelaçado a este tema está o conceito de mundialização, que é considerado sinônimo ou especificação da globalização. Para Alain Touraine, citado por Lima Torrado, a mundialização seria a prolongação das tendências de abertura que se aceleraram na segunda parte do século XX, enquanto a globalização seria o processo nefasto mediante o qual os povos cederam poder sobre suas economias a forças globais e antidemocráticas, como os mercados.

A globalização começa com o caráter econômico, com a liberação dos intercâmbios comerciais e do aumento de investimentos, além da integração de mercados financeiros, seguindo para o âmbito jurídico-político, com a perda de poder de gestão dos estados nacionais acerca de sua política econômica, afetando até a soberania. Essa economia global cria interdependências e assimetrias.

O professor espanhol Manuel Castells, um estudioso das questões da nova sociedade de informações, tenta elucidar o funcionamento deste processo:

\begin{abstract}
(...) la era de la globalización de la economía es también la era de la localización de la política. Lo que a los gobiernos locales y regionales les falta en poder y recursos, lo suplen con flexibilidad e interconexión. Ellos son los únicos que pueden estar a la altura del dinamismo de las redes globales de riqueza e información (in TORRADO, 2000, p. 51).
\end{abstract}

A perda da soberania estatal abre caminho para o exercício dessas competências por meio de entidades supraestatais de natureza internacional, como é o caso de órgãos que se dedicam à regulação de questões econômicas multilaterais, como a Organização Mundial do Comércio, o Banco Mundial e do Fundo Monetário Internacional.

Os impactos da globalização ainda se estendem aos processos culturais e ideológicos, sendo observados a aculturação, a perda da identidade cultural e a perda da referência psicológica do sujeito na pós-modernidade.

Los valores de equidad, participación y solidaridad que pretendían constituirse en la base del consenso en las relaciones internacionales en el periodo de tiempo comprendido entre la Revolución Industrial y el final de la guerra fría son ahora sustituidos por nuevos valores que constituyen su antítesis y el cierre del Estado social de Derecho. Esos valores son fundamentalmente tres: eficiencia, competitividad y libre mercado (TORRADO, 2000, p.57).

Esta compreensão é complementada pelo pensamento de Zigmunt Bauman, quando considera esse processo como próprio da evolução histórica dos Estados modernos. Esclarece que ocorre a passagem da modernidade "sólida", centrada em soberania territorial e impermeável, para a modernidade "líquida", onde caem as fronteiras que se tornam difusas e permeáveis, acabando por fragilizar a própria capacidade de defesa dos Estados. 
A globalização nesse contexto incita a humanidade a "viver sem um centro, embora essa ausência de um poder global claro, incontestado e de autoridade inquestionável gere, para os poderosos e os soberbos, uma constante tentação de buscar, eles próprios, preencher esse vazio" (BAUMAN, 2008, p. 11).

Boaventura de Souza Santos preceitua criticamente a globalização como sendo: "um processo pelo qual determinada condição ou entidade local consegue estender sua influência a todo o globo e, ao fazê-lo, desenvolve a capacidade de designar como local outra condição social ou entidade rival" (SOUSA SANTOS, 1997, p. 108). Segundo ele, a globalização produz transformações que comprimem a noção espaço-tempo, mas que devem ser analisadas no contexto das relações de poder.

O professor Santos acredita que em alguns momentos e para classes capitalistas, a globalização pode favorecer; enquanto que para as classes marginalizadas, a globalização não favorece, pois não muda a realidade social. Sustenta ainda existir uma divisão internacional da produção da globalização países centrais se especializam em localismos globalizados (exportam), enquanto aos países periféricos se impõe os globalismos localizados (importam).

A esse binômio da globalização, Souza Santos acrescenta o cosmopolitismo (diálogos e coletivos de interação transnacional em defesa de interesses comuns) e os temas emergentes que se constituem patrimônio comum da humanidade e sua globalidade ganha sentido exatamente quando vista do ponto de vista de sua totalidade (biodiversidade, temas ambientais).

Essa estrutura tem funcionado ainda com base em um elemento diferenciado de outros tempos históricos, a informação. Ela tem sido o principal subsídio da era contemporânea para amparar e acelerar o processo de globalização de eventos, estruturas, sentimentos e pensamentos.

O homem passou a integrar uma sociedade da informação, conceito do final da década de 1960 que procurava explicar os impactos tecnológicos nas relações de poder. Com a evolução acelerada da tecnologia, este modelo evoluiu para o que se denomina sociedade em rede, que opera dentro de um padrão de interação e de organização social onde a informação é o elemento-chave e o fluxo de mensagens em rede constitui a base da estrutura social, que é a marca da Era da Informação.

A sociedade da informação apresenta algumas características, conforme preceitua o pesquisador português Luis Manuel Borges Gouveia: a utilização da informação como recurso estratégico; a utilização intensiva das tecnologias de informação e comunicação; a 
interação entre indivíduos e instituições tem o predomínio digital; e a possibilidade de usar o meio digital para criar ou realizar tarefas convencionais da vida do homem.

O que ocorre nesse encontro entre globalização e mundo digital é próximo à visão futurista que parecia ficção no final da década de 1940, quando foi escrito o romance de George Orwell, denominado "1984”. E, ainda, o prenúncio do que já alertava Marshall McLuhan em “O Meio é a Mensagem”, publicado em 1964. O alerta era de que a tecnologia poderia alterar a maneira como o homem se relaciona com a realidade, causando impactos e desajustes em cadeia.

A internet se tornou um fenômeno fundamental para a globalização e está sendo um fator que aprofunda as desigualdades sociais, levando ainda o ser humano a perder o seu lugar no mundo. Instaura-se um cenário com consequências ideológicas, onde a maioria da população fica exposta quase que permanentemente a ações globalizantes e se afasta do conhecimento de sua própria identidade, de antecedentes, características e necessidades.

A expansão tecnológica levou o futuro se tornar o próximo e fugaz, dando ao indivíduo a impressão de navegar em um mar aberto e ilimitado de possibilidades a partir da informação. A era informacional oferece às forças hegemônicas, no âmbito econômico e político, o espaço para a disseminação de ideias e modelos de comportamento que acabam por acentuar assimetrias e globalizar princípios e culturas.

De outro lado, aloca um modelo multifacetado de interação social, onde as estruturas formais se diluíram e a centralidade ficou pulverizada. Nesse contexto, os indivíduos se reúnem em torno de pautas e interesses voláteis e se distraem com a efemeridade dos conflitos, buscando eles mesmo serem parte do problema e da solução.

Seguindo as reflexões de Bauman, parece relevante reformular esse novo espaço público global, que opera a partir do valor das informações e em rede. Busca-se agregar à globalização uma dimensão crítica, fomentando a assunção de responsabilidades planetárias, que envolvem a consciência de que há interdependência entre os seres, entre as economias, e que a resposta limitada ao espaço local é insuficiente para solucionar as questões que afetam toda a humanidade.

A lógica de responsabilidade planetária está voltada, pelo menos em princípio, para tomar os problemas gerados globalmente e os enfrentar à queima-roupa - em seu próprio nível. Ela se origina da suposição de que soluções duradouras e efetivas para problemas de dimensões planetárias podem ser encontradas e postas para funcionar apenas por meio da renegociação e da reforma da teia de interdependências e interações globais (BAUMAN, 2008, p. 23). 
Pensar a globalização a partir dessa lógica responsável permite equalizar conflitos e o contraditório dentro desse modelo de nova civilização, buscando meios para compreender que a interconexão necessária deve seguir a noção de sustentabilidade, ética e respeito à dignidade humana e às diferenças. Nesse sentido, a sociedade da informação não pode simplesmente abastecer a coletividade e automatizar o comportamento e o pensamento humanos. É seu dever alimentar a rede de seres de informações e meios de compreensão, capazes de gerar a crítica sobre a própria realidade.

\section{Os impactos da globalização nos Direitos Humanos}

Os processos de globalização têm afetado as bases metodológicas e doutrinárias do Direito, calcadas na predominância do Estado como o soberano e central na prestação jurisdicional. Uma nova sociedade emerge do processo de globalização e seus produtos e resultados penetram o tecido social dos países, afetando direitos e em especial direitos humanos em suas sucessivas gerações.

A sociedade em rede levou à incorporação de novos valores à hierarquia normativa e fez-se somar aos conceitos de regulação e sanção, muito próprios do poder estatal tradicional, a necessidade de promover ambientes para comunicação, cooperação e coordenação.

Pode-se verificar os efeitos da globalização nos direitos mais próprios à individualidade, como o direito à informação, à privacidade e ao desenvolvimento da pessoa; e no campo coletivo, no direito ao trabalho. Manifestam-se, ainda, na dimensão de valores difusos, como o direito ao desenvolvimento, à autodeterminação dos povos, além do direito ao meio ambiente e à paz.

Segundo Lima Torrado, os direitos humanos de segunda geração foram bastante atacados no processo de globalização, que trouxe consideráveis mudanças nas relações de trabalho, gerando como consequências a agravação da transversalidade do desequilíbrio e pobreza entre o norte e o sul. A globalização tem promovido a concentração da riqueza, alargando a distância entre países desenvolvidos e os demais. E, juntamente com a revolução tecnológica e científica, tem pressionado sobretudo os sistemas sociais, reduzindo sobremaneira os postos de emprego.

A globalização dita novos padrões e aparelha uma organização própria de valores que desafiam o sistema de direitos humanos. Bauman, por exemplo, constata que na sociedade atual os valores vão se revezando e a igualdade de outrora cedeu lugar à paridade, 
que é a condição de equidade em ter direitos reconhecidos. Este autor fala sobre o mundo líquido da atualidade, onde os conceitos mais tangíveis cedem lugar à transitoriedade e flexibilidade de conteúdos, criando esse movimento de estar em constante e fácil mutação.

Tamanha fluidez em conteúdos impacta na formação das identidades e nos direitos humanos, pois sua inconstância exige um processo de contínua renegociação de valores e conceitos. Com isso, os direitos se desconectam de sua dimensão crítica e se tornam suporte para uma estratégia de dominação, que ao final pode almejar globalizar o pensamento.

De forma reativa, surgem movimentos proativos para fazer frente à globalização, como os movimentos feministas e em defesa do meio ambiente. Atores internacionais, como organismos internacionais e entidades não-governamentais, vêm dando atenção aos impactos da globalização e especificamente atentos ao que ocorre no mundo digital.

A partir de parâmetros como a representatividade e a transparência nas questões econômicas, acredita-se ser possível construir de forma progressiva uma sociedade civil global. Lima Torrado vislumbra que:

\begin{abstract}
La transformación de este rechazo en la reconstrucción de nuevas formas de control social sobre las nuevas formas de capitalismo, globalizado e informatizado, requiere que el sistema político y las instituciones estatales procesen las demandas de los movimientos sociales. La capacidad o incapacidad del Estado para afrontar las lógicas conflictivas del capitalismo global, los movimientos sociales basados en la identidad y los movimientos defensivos de los trabajadores y consumidores, condicionará en buena medida el futuro de la sociedad en el siglo XXI) (TORRADO, 2000, p. 64).
\end{abstract}

Caminha-se para reforçar uma pauta de responsabilidade social nos processos econômicos globais e privados e de construção de uma estrutura mais igualitária de governança da globalização. Por essa trilha de construção política e social, abre-se um espaço para desenvolver a crítica aos direitos humanos, identificando as diversas formas de opressão e os recursos existentes para a mudança, incluindo novos atores e uma nova forma de pensar o direito, de dentro para fora.

\title{
4 A proteção dos direitos humanos na sociedade da informação
}

A interdependência e assimetria da globalização que acentuaram a divisão NorteSul da sociedade e colocaram o sistema de direitos humanos em alerta, tem na revolução tecnológica um elemento de contrassenso: enquanto acelera e democratiza acessos a serviços e funcionalidades do mundo contemporâneo, desequilibra ainda mais as relações sociais. 
Na sociedade da informação que surge desse processo global ocorre um dinâmica de concentração de poder e alguns fatos recentes, como as denúncias de uso de informações para viabilizar projetos políticos de impacto global, deram notícia das fragilidades dos direitos em face desse "boom" tecnológico. Os cidadãos que vivem nessa rede têm seus dados pessoais processados e convertidos em ferramentas de persuasão econômica, política e comportamental.

A preocupação é tamanha sobre a proteção dos direitos humanos no ambiente digital que o tema foi objeto de relatório da Organização das Nações Unidas (ONU) e de resolução de seu Conselho de Direitos Humanos em 2019. O relatório do Secretário-Geral da ONU denominado “A Era da Interdependência Digital” recomenda uma revisão global para conformar as normas de direitos humanos à tecnologia digital, o que implicaria cooperação também dos setores empresariais e detentores de tecnologia e informações.

O relatório já descreve as razões para subscrever tal desafio:

Digital technologies are rapidly transforming society, simultaneously allowing for
unprecedented advances in the human condition and giving rise to profound new
challenges. Growing opportunities created by the application of digital technologies
are paralleled by stark abuses and unintended consequences. Digital dividends co-
exist with digital divides. And, as technological change has accelerated, the
mechanisms for cooperation and governance of this landscape have failed to keep
pace. Divergent approaches and ad hoc responses threaten to fragment the
interconnectedness that defines the digital age, leading to competing standards and
approaches, lessening trust and discouraging cooperation (ONU, 2019, p. 4).

No que concerne ao mundo digital, a ONU aponta no relatório ações prioritárias que devem ser objeto de atenção mais imediata: a construção de uma economia e de uma sociedade com inclusão digital; o estabelecimento de capacidades humanas e institucionais para essa finalidade; a estruturação institucional de garantias à proteção dos direitos humanos no mundo digital; o compromisso com a confiança, a segurança e estabilidade nesse ambiente tecnológico; o desenvolvimento de mecanismos globais de cooperação digital.

Conforme o relatório os direitos humanos se aplicam completamente ao mundo digital e por isso a urgência nas medidas de adaptação das legislações e acordos internacionais sobre direitos humanos às tecnologias digitais emergentes.

A resolução 42/15, do Conselho de Direitos Humanos, aprovada em 26 de setembro de 2019, trata mais especificamente do direito à privacidade. E apresenta uma série de solicitações aos Estados-membros, desde a revisão normativa e procedimental; medidas para evitar violações e abusos do direito à privacidade por meio do uso de informações; desenvolvimento de ambiente cooperativo com o setor privado para proteção desses direitos; 
estabelecimento de salvaguardas para a proteção de dados, de natureza administrativa, técnica e física, garantindo a integridade e confiabilidade do processamento de dados pessoais para propósitos legítimos. E, de forma proativa, colocar os direitos humanos dentro da própria tecnologia, ao solicitar:

(e) To ensure that the respect for the right to privacy and other relevant human rights decision-making and machine-learning technologies, and to provide compensation for human rights abuses that they have caused or to which they have contributed; (ONU - Human Rights Council, 2009, p. 2)

$\mathrm{O}$ ponto de reflexão da ONU é no sentido de que as tecnologias digitais promovam realmente melhorias de vida de forma igualitária. E para tal, há necessidade de despertar a sociedade civil, as empresas e os governos sobre essa interdependência e necessidade de cooperação para que isso se concretize, em respeito à dignidade humana e sustentabilidade da própria existência social.

Os benefícios e vulnerabilidades advindos do avanço do poder computacional e da interconectividade na era digital reforçam o caráter de interconexão, em nível global e local, que já se verificava nas questões econômicas e nas pautas sociais e ambientais. Isso leva a crer que soluções sobre proteção dos direitos nesse universo digital devam ser pensadas com respeito a diferenças e peculiaridades de cada grupo humano, buscando primar pela liberdade e pela capacidade de autodeterminação do indivíduo, inclusive em termos informativos.

O Brasil também vem tomando medidas para proteger os direitos humanos na sociedade da informação, tendo aprovado em agosto de 2018 a Lei n ${ }^{0} 13.709$ - a Lei Geral de Proteção de Dados Pessoais (LGPD). É a primeira legislação mais específica que, ao lado de marcos legais como a Lei ${ }^{\circ} 12.965$ de abril de 2014 (conhecida como o Marco Civil da Internet), busca implementar um ambiente de regulação para o mundo digital, atentando especificamente para os direitos humanos previstos constitucionalmente.

A LGPD explicita o objetivo de proteger os direitos fundamentais de liberdade e de privacidade e o livre desenvolvimento da personalidade da pessoa natural, tendo por o respeito à privacidade; a autodeterminação informativa; a liberdade de expressão, de informação, de comunicação e de opinião; a inviolabilidade da intimidade, da honra e da imagem; o desenvolvimento econômico e tecnológico e a inovação; a livre iniciativa, a livre concorrência e a defesa do consumidor; e os direitos humanos, o livre desenvolvimento da personalidade, a dignidade e o exercício da cidadania pelas pessoas naturais.

Sua entrada em vigor no mês de agosto de 2020 iniciou um novo momento para a sociedade brasileira, sobretudo nas relações de consumo, e estão postos os desafios para a 
Autoridade Nacional de Proteção de Dados nela prevista, estrutura formal que pretende ser o guardião dos direitos no que tange aos objetivos dessa lei. E, no sentido do que preconiza a ONU, outras medidas precisam ser objeto de atenção acerca da proteção a direitos no mundo digital, haja vista se tratar de uma questão de natureza ampla, capaz de representar ameaça às bases de uma sociedade plena no exercício de sua dignidade e capacidades.

\section{Conclusão}

Focalizar a globalização e a sociedade da informação com o olhar dos direitos humanos é a oportunidade de humanizar as relações civilizatórias dos novos tempos, onde praticamente toda a vida em sociedade está se desenvolvendo aqui e ali, querendo dizer no território presente e ausente, distante e próximo, real e virtual. Parece até mais um cenário fantástico da ficção dos romances e filmes, mas simplesmente acontece aos olhos de qualquer expectador.

O interessante dessa nova civilização é que, ciente ou não das estratégias hegemônicas que invadem sua privacidade com teorias, produtos e tendências, esse ambiente digital possibilita coletividades dispersas geograficamente se aglutinarem para fazer resistência a pautas múltiplas. Exemplos disso são o enfrentamento ao racismo, cujas manifestações globais tiveram origem em junho de 2020 em Minnesota nos Estados Unidos, ou a proteção ao meio ambiente e aos direitos das mulheres.

Tais manifestações parecem configurar o exercício da resistência à opressão, como descrita por Norberto Bobbio, sendo este contraponto o condutor da história dos homens para outros estágios de desenvolvimento. Convivendo com esse processo negação dos atuais valores do Estado e da sociedade estão outros construtos, de natureza conservadora e visão hegemônica, que seriam a reação dos poderes instituídos e sua tentativa de controlar as demandas nascidas da contestação social.

Reside aí a mística da sociedade em rede, interdependente e em ritmo acelerado de mudanças por conta do desenvolvimento tecnológico. Permite o exercício de liberdades de diferentes naturezas, em um presente que rapidamente se substitui por outro.

As modernas tecnologias podem ser utilizadas, como já se constatou, para violar a privacidade e a segurança dos indivíduos. Contudo, seus impactos não estão restritos ao campo dos direitos de privacidade e liberdade, mais próximos da natureza individual do homem. Revelam suas sequelas ao processo de estruturação social, envolvendo direitos de 
fundo coletivo e difuso, ao provocar transformações em sistemas educacionais e no mercado de trabalho, com resultados positivos e outros nem tanto, como é o caso da indiscriminada automação.

Proteger a dignidade humana nesta dinâmica global começa por entender a sociedade da informação, o movimento, as vulnerabilidades e as oportunidades que se apresentam. Esse olhar desperto e crítico sobre o processo global e informacional apoia a identificação do núcleo de direitos humanos a serem protegidos e os mecanismos normativos que carecem de ajuste para atuar nessa realidade civilizatória.

Estariam então mais consolidados os pilares para permitir à sociedade avançar no uso da tecnologia de forma objetivando melhorar a vida das pessoas e criar um ambiente de confiança e harmonia de interesses. E, desse processo, seria possível construir uma trilha de cooperação tecnológica, política, econômica e cultural que aproveite o oceano da interconectividade para propor soluções efetivas e equânimes para os problemas do mundo.

\section{Referências}

BAUMAN, Zygmunt. A ética é possível num mundo de consumidores? Jorge Zahar Editor Ltda, 2013.

BOBBIO, Norberto. A era dos direitos. Rio de Janeiro: Campus, 2005.

BRASIL. Lei ${ }^{\circ}$ 13.709, de 14 de agosto de 2018. Lei Geral de Proteção de Dados Pessoais. Diário Oficial da República Federativa do Brasil, Brasília, DF, 15 ago. 2018. Disponível em: http://www.planalto.gov.br/ccivil_03/_ato2015-2018/2018/lei/L13709.html . Acesso em: 13 jun. 2020.

CASTELLS, Manuel. Reflexions on the Internet, Business, and Society. Oxford Press, 2002.

GOUVEIA, Luis Manuel Borges. Sociedade da Informação - Notas de contribuição para uma definição operacional. Disponível em: http://homepage.ufp.pt/lmbg/lg_com2.htm. Acesso em: 20 jun. 2020.

MCLUHAN, Marshall. O meio é a mensagem - Os meios de comunicação como extensões do homem. 9. ed. São Paulo: Cultrix, 20ª ed. 2011.

ORGANIZAÇÃO DAS NAÇÕES UNIDAS. The age of digital interdependence - Report of the UN Secretary-General's High-level Panel on Digital Cooperation. Disponível em: https://www.un.org/en/pdfs/DigitalCooperation-report-for\%20web.pdf. Acesso em: 20 jun. 2020 . 
ORGANIZAÇÃO DAS NAÇÕES UNIDAS. Comissão de Direitos Humanos. Resolução 42/15 - The right to privacy in the digital age. Disponível em: https://documents-ddsny.un.org/doc/UNDOC/LTD/G19/282/23/PDF/G1928223.pdf?OpenElement. Acesso em: 13 jun. 2020.

SOUSA SANTOS, Boaventura de. Por uma concepção multicultural de direitos humanos. São Paulo: Revista Lua Nova. Vol. 39, 1997.

TORRADO, Jesus Lima. Globalización y Derechos Humanos. Anuário del filosofía del derecho: 2000. Disponível em: https://dialnet.unirioja.es/descarga/articulo/142424.pdf. Acesso em: 20 jun. 2020.

Data de recebimento: 01.08.2020

Data de aprovação: 07.10.2020 